\title{
Highlighting Best Practices in Promoting Diversity, Inclusion, and Civility in STEM
}

\author{
Jenifer S. (Warner) Locke
}

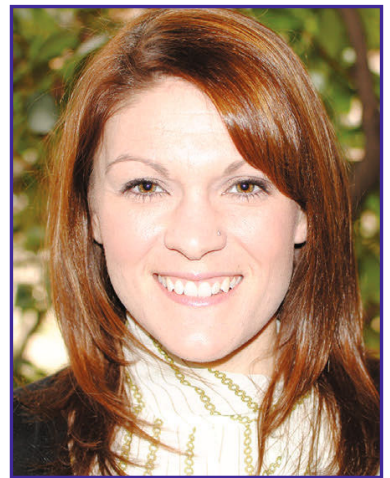

Jenifer Locke

"Highlighting Best

Practices in Promoting

Diversity, Inclusion, and Civility in STEM" serves as in introduction to a thematic group of articles in the September 2020 issue of $J O M$ covering diversity and inclusion topics. The article package is a feature series developed by the TMS Diversity, Equity, and Inclusion Committee. For additional information, contact Kaitlin Calva, JOM Magazine Managing Editor, at kcalva@tms.org.
I think all people who are underrepresented in their career field, be it because of gender, race, LGBTQ+, religious orientation, country of origin, disability status, etc., will share a common experience of knowing something should be done better, but not really knowing how. This feeling of uncertainty, of only knowing that how something is currently done isn't working for a specific group of people, can halt our ability to speak for ourselves and others. I personally find this to be particularly true for data- and fact-driven people, like the scientists and engineers who make up the TMS membership. We have a feeling, but don't have facts and examples to show a different path forward, so we remain silent. The goal of this special article series from the TMS Diversity, Equity, and Inclusion Committee is to provide us all with some data and best practices on efforts occurring within our communities to improve representation and retention of minorities in STEM. It is my hope that the following four articles can provide data and facts to propel $J O M$ readers' voices and help them enact change in their workplaces and communities.

The first article, written by Teri Reed et al., addresses the need to end harassment in our workplaces and communities. In this article you will learn about civility audits and results, find what gaps exists in these surveys and steps the authors are taking to fill these gaps, and read the promising practices these researchers have found over the past years.

Next, Aeriel Murphy-Leonard details how a group of graduate students has taken outreach to the next level through the Liberian Society for Women Engineers SUCCESS Camp to increase the representation of women in engineering in Liberia. This article will inspire you to broaden your thinking on approaches to increasing representation.

The third article, written by Mary
Juhas and Caroline Crisafulli, outlines a successful initiative called REACH for Commercialization that works to strategically address and repair the gender gap in commercialization, translating research to startup success, and patenting. As this program expands outside of its local community, its increased visibility can provide readers with a tool to infuse their inventions and startups with fresh and diverse ideas.

The last article, by Whitney Gaskins et al., focuses on successful efforts taken by The Gaskins Foundation at all levels of $\mathrm{K}-12$ education to increase representation of underrepresented minorities, particularly Black and Latinx, in STEM. The Foundation's work shows that individualizing approaches to specific age groups and targeting the needs of the whole person are translating into real success. This article makes connections with a growing foundation that can help create a best practice outreach program in your own community.

While the enclosed highlight just a few of the best practices, we know there is more being done and so much more to do. As we are all seeing and voicing our support for the rise of Civil Rights movements, like Black Lives Matter, I hope these articles provide a starting place for having those tough conversations or identifying a path to success.

Jenifer S. Locke is an assistant professor in the Department of Materials Science and Engineering and the Fontana Corrosion Center at The Ohio State University. As a TMS member, she is actively involved in the Diversity, Equity, and Inclusion (DEI) Committee, for which she curated this article series. Locke would like to thank the DEI committee members and the authors featured in this article series for their work in putting together this special topic.

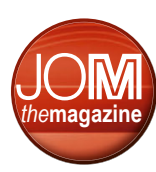

